J. OF PUBLIC BUDGETING, ACCOUNTING \& FINANCIAL MANAGEMENT, 20 (2), 141-152 S SUMMER 2008

\title{
CLARIFICATION OF THE SOCIAL COSTS OF GAMBLING
}

\author{
Douglas M. Walker*
}

ABSTRACT. As U.S. states and countries around the world consider legalizing casino gambling, the social costs of gambling continue to be hotly debated. This paper examines the social cost issue from a welfare economics perspective, and discusses the 2005 paper by Thompson and Schwer, published in this Journal. Their article exhibits a number of problems common in gambling research, including a flawed conception of social costs and a variety of measurement errors. For example, Thompson and Schwer count many costs borne by individuals as "social costs." In addition, many of their cost estimates appear to be arbitrary. As a result, the Thompson and Schwer social cost estimate is likely a serious overstatement of the actual costs.

\section{INTRODUCTION}

In this journal's 2005 symposium on gambling, Thompson and Schwer (2005) published "Beyond the limits of recreation: Social costs of gambling in southern Nevada." Their paper addresses a very important issue in the ongoing debate over legalized gambling. They provide a dollar estimate of the annual social costs per pathological gambler in southern Nevada. This type of study can provide data for policymakers and other researchers attempting to weigh the costs against the benefits of legalized gambling. Because social cost estimates are difficult to produce, both in terms of data collection and choosing the appropriate methodology, there have been few legitimate estimates to appear in the literature. This means that any new estimates are likely to receive a significant amount of attention from media, government, and industry.

* Douglas M. Walker, Ph.D., is an Associate Professor, Department of Economics and Finance, College of Charleston. His research interest is in the economic effects of gambling.

Copyright $\odot 2008$ by PrAcademics Press 
Readers who are not familiar with the economics of gambling literature should read some of the papers in this area to gain perspective on how the academic debate over legalized gambling has developed since the mid-1990s. What makes this field so interesting is that the spread of casino gambling in the U.S. in the early-mid 1990s really jump-started research on the economics of gambling. So it is a relatively new field, and it is full of controversy. The newness of the casino industry in the U.S. has provided a great experiment that deserves much more study than it has received to date.

In this paper, the author reiterates the importance of properly defining "social costs," so that citizens and policymakers have a better understanding of social cost estimates. Application to the Thompson and Schwer (2005) example gives the reader a real-world picture of the sometimes-abstract concept of social costs from the economics literature. This endeavor may also help future social cost researchers and policymakers understand some of pitfalls in performing social cost estimates. ${ }^{1}$

\section{THE DEFINITION OF “SOCIAL COST": A RESTATEMENT²}

The gambling literature has lacked a consensus on the definition of "social cost," though there have been serious attempts to come to an agreement. ${ }^{3}$ With no standardized definition, interpreting and comparing social cost estimates can be tricky. Walker and Barnett (1999) offer a social cost methodology based on the economics literature and Walker (2003) provides a principles-level explanation accessible to non-economists. The goal of these papers was to offer a standardized social cost methodology to help facilitate sound social cost estimates and make their interpretation more straightforward.

"Social cost" has a very specific meaning in economics. It is a decrease in total societal wealth attributable to some action or government policy, or in this case, to the existence of pathological gambling. ${ }^{4}$

Walker (2003, p. 162) explains that civil court, criminal justice, and therapy costs are among the potential measurable social costs of pathological gambling. Why are these social costs? If pathological gambling did not exist, the civil court, criminal justice, and therapy costs would not have been incurred. The lawyers involved could have otherwise been writing contracts, for example, and some 
psychiatrists' time could have instead been used to do research. Since pathological gambling exists, resources are diverted from other (productive) uses into court proceedings and treatment for pathological gamblers. This causes less output, in terms of contract writing and psychiatric research. This lost output represents a social cost because it is a decrease in the society's real wealth.

There are certainly other negative consequences from problem or pathological gambling. These might include emotional problems, personal problems with friends and family members, problems on the job and with creditors, among other problems. As terrible as these problems may be, most of them are "internalized." That is, there is no social aspect to them. The consequences fall either on the gambler himself, or on others who have voluntarily entered into agreements or transactions with him. As a result the residual claimant of these losses is a private individual, not "society."

Another thorny area is that of wealth transfers. These are simply transfers from one person to another. The National Research Council (1999, p. 163) explains, "One of the biggest stumbling blocks in economic impact analysis is determining which effects are real and which are merely transfers." Certainly it is bad for a creditor when a pathological gambler fails to pay off debt. But when the money was borrowed, the creditor took a risk in loaning the money. If the debtor fails to pay back the loan, the loss to the creditor is offset by the debtor's gain. There is no net change in the level of societal wealth. This is not to say that there are not consequences for defaulting on loans. But the consequences fall on private individuals or on society only through the adjustment of prices. ${ }^{5}$

It is critical in social cost studies to start by stating an explicit definition of social cost. In the absence of a definition, researchers tend to utilize ad hoc methodologies that suit their data or their biases about gambling.

\section{EXAMPLE: THOMPSON AND SCHWER}

Thompson and Schwer (2005) use a survey of 99 Las Vegas Gamblers Anonymous members as a basis for their social cost of gambling estimate. In their survey they ask a number of demographic questions, as well as questions about how the respondents' gambling 
problems were related to their criminal activities, financial problems, personal and family problems, and employment.

The authors indicate they rely on an earlier study (Thompson, Gazel, and Rickman, 1996) for deriving many of their cost calculations, without explaining the methodology utilized in the earlier report. To my knowledge, those estimates (and that study) have not undergone peer review. Reliance on such studies is a major problem in gambling research, as explained by the NRC (1999, p. 185): “In most of the impact analyses...the methods used are so inadequate as to invalidate the conclusions. Researchers...have struggled with the absence of systematic data that could inform their analysis and consequently have substituted assumptions for their missing data."

Rather than dissecting the specific dollar estimates, ${ }^{6}$ the focus here will be the types of costs included in the Thompson and Schwer (2005) study, and whether they can legitimately be considered to be "social costs." Whether or not a particular cost qualifies as "social" in nature, Thompson and Schwer have identified a number of negative consequences that may result from pathological gambling. The issue is whether the cost leads to a reduction in societal wealth, or whether the loss is "internalized" by the pathological gambler or a party who enters into a voluntary transaction with him.

Thompson and Schwer (2005, Table 7, p. 83) estimate the annual social cost per pathological gambler at $\$ 19,711$. The different cost categories are: "employment costs," "debts, bankruptcies and civil suits," "thefts and criminal system actions," "treatment," and "welfare services." We examine the components of each of these categories below.

\section{Employment Costs}

It is unclear exactly what the "cost of lost work" represents. But it appears that Thompson and Schwer (2005) estimate the lost wages to employees who do not work due to their gambling problems. But like productivity losses and firings, these "costs" are completely private in nature, falling on the employee or employer. There is no social or external aspect to it.

To see this, consider an example. Suppose Joe works at a factory producing widgets, priced at $\$ 1$ each. His average output is 50 widgets per 8-hour working day. The value of his production each day 
is $\$ 50$. Thompson and Schwer appear to believe that if he skips a day of work, it would result in a social cost. This would presumably be true whether he missed work because he was playing slot machines all day, or playing golf.

The focus on tangible output is misguided. If we are going to classify "not working" as a social cost, then we should be even more concerned with the costs of sleeping at night, taking vacations, and retirement, since all of these result in less tangible output than we might have had otherwise. ${ }^{7}$

If we think about the worker-employer relationship and their transaction (i.e., their labor contract), the view that missed work is a social cost must be flawed. If Joe decides not to show up for work one day, there are several possibilities. First, perhaps his employer will refuse to pay him. In this case, all that has happened is that a transaction that would have occurred did not, because Joe did not go to work. Second, if his employer pays him even if he skips work, then his employer incurs the cost. The same argument applies to productivity losses. If his employer does not reduce his pay or fire him as a result of his decreased performance, then the employer bears the burden of the cost. It is "internalized," and is therefore not a social cost. 8

For the reasons discussed above, missed work, quitting jobs, and fired jobs should be removed from the social cost estimate. Although Thompson and Schwer (2005, pp. 77, 79) indicate that decreased worker productivity for those who keep their jobs should also be included in the cost estimate, it is clear that such productivity decreases would also be internalized. Such costs should not be included in the estimated social cost of gambling.

The only cost associated with employment that could legitimately be classified as a social cost is the administrative costs associated with unemployment benefits being paid. The benefits themselves are wealth transfers, but a portion of the cost of administering the system would appropriately be classified as a social cost. However, Thompson and Schwer (2005) do not estimate this specific cost.

\section{Debts, Bankruptcies and Civil Suits}

Bad debts are wealth transfers, and should be omitted from the social cost estimate. We may all agree that it is unfortunate that the 
transfer occurs. But it is not a decrease in the society's wealth because the same amount of wealth still exists-only it has changed hands. For this reason, Walker and Barnett (1999) explain, neither voluntary nor involuntary transfers can be considered social costs. The Federal Reserve Bank of Minneapolis report (2003, p. 8) reiterates Walker and Barnett's argument, which criticizes Thompson Gazel, and Rickman (1996) for counting transfers as social costs.

Walker (2003, pp. 165-166) provides a 3-case example to illustrate conceptually why transfers cannot be considered to be social costs. Suppose Joe is a pathological gambler and that he (1) receives a $\$ 20$ "bailout" from his father Sam, (2) defaults on a \$20 loan from Sam the banker, or (3) receives a $\$ 20$ check from the government, financed by Sam's taxes. The cases represent behavior that is "voluntary" to different degrees. Each of the three cases is a transfer and not a decrease in the society's wealth. ${ }^{9}$

Despite the amount of the bad debt being excluded from the social cost total, any court costs associated with bankruptcies and civil suits, to the extent they can be attributed to pathological gambling, would be social costs. However, the cost estimated by Thompson and Schwer for bankruptcy and civil suit proceedings is somewhat arbitrary. They explain (p. 82), "There were 44 bankruptcy actions. There were also 19 civil suits relating to debts (reported by 93 respondents). The earlier study found that each federal court action costs $\$ 7,500$. Considering that these actions may not be as complicated or long enduring as some others, we assign a $50 \%$ cost factor of $\$ 3,750$ for each of the 63 cases." This is the type of cost estimate that the NRC (1999, p. 185) was criticizing because it is based on arbitrary assumptions.

\section{Thefts and Criminal System Actions}

Thompson and Schwer (2005) ignore the literature dealing with the social costs of theft. Since theft represents a transfer of wealth, it should not be included in social cost estimates (Walker and Barnett, 1999). However, the administrative and court costs associated with criminal activities, e.g., arrests-to the extent they are attributable to problem gambling-would be considered social costs. ${ }^{10}$ If incarceration and probation are due to the gambling problem, then these costs would also be considered social costs. 


\section{Social Costs of Treatment}

As indicated by Walker and Barnett (1999), treatment cost is considered a social cost of gambling problems.

\section{Welfare Services}

Welfare payments are conceptually like theft-they are transfers. However, the administrative costs associated with the welfare system can be counted as social costs. Unfortunately, these costs are extremely difficult to estimate.

\section{A Revised Social Cost Estimate}

After considering the various effects in the context of the economics definition of social costs, most of the effects identified by Thompson and Schwer (2005) turn out to be private or internalized costs and thus should be removed from the social cost estimate. Without debating how they arrive at their specific dollar estimates, the social cost estimate would be reduced to $\$ 1,579$ by eliminating transfers and private costs. Taking for granted the prevalence estimates and related calculations by Thompson and Schwer (2005), the cumulative social costs for southern Nevada would be revised from $\$ 314-545$ million down to $\$ 25-44$ million per year. ${ }^{11}$

\section{MISAPPLICATION OF ECONOMIC CONCEPTS}

There are several aspects of the Thompson and Schwer social cost estimate that make it an untraditional measure, at least from an economic perspective. The authors misapply several important economic concepts. Two examples follow. As a result of these quirks, interpretation of their social cost estimate may be difficult.

Thompson and Schwer (2005, p. 89, Table 10) categorize the costs as "economic," "government" and "social." Their goal is to indicate who bears the various costs (p. 75). But then they sum these different costs, and the reader is left at the end inferring that the social cost of gambling is $\$ 19,711$ (Thompson and Schwer, 2005, Appendix A, p. 93). They estimate the costs to government as a result of pathological gambling at $\$ 22-39$ million. But suggesting that this is a social cost is inappropriate. If government spending did represent a social cost, then we could simply reduce social costs by paring government spending (Walker, 2003). This illustrates why the 
definition of social cost matters. Thompson and Schwer adopt a definition that creates confusion.

Thompson and Schwer make reference to "deadweight losses," but do not use the term as it is normally used in the economics literature. For example, they refer to increased interest rates caused by loan defaults as a deadweight loss (p. 90). This is an example of a pecuniary externality, not a deadweight loss.

These are but two examples of the misapplication of economic concepts in the Thompson and Schwer paper. Walker (2007) provides a detailed analysis of these types of problems, and others that have appeared in the literature.

\section{CONCLUSION}

Clearly Thompson and Schwer (2005, p. 66) have identified some of the significant issues in the gambling debate, "...there are definitional questions. What should we call the 'costs,' 'social costs,' 'societal financial burdens,' 'economic costs,' 'dead weight costs,' 'net social costs'? Further there are questions regarding methodologies for determining costs." The methodological foundation for their analysis is adopted from Politzer, Morrow, and Leavey (1985), ${ }^{12}$ Thompson, Gazel, and Rickman (1996; 1999), and Thompson and Quinn (1999).

The National Research Council (1999)13 and the Federal Reserve Bank of Minneapolis (2003) have both discussed some of the major stumbling blocks in the social cost of gambling research. Since these critiques, there have been significant advances in our understanding of the social costs of gambling. Much of the development in this area has been due to the application of ideas from the economics and substance abuse literature. Yet, Thompson and Schwer do not appear to consult any of this work in developing their own social cost methodology. ${ }^{14}$ Instead of relying on an established literature, they appear to rely mostly on arbitrary assumptions. Readers of the Journal should be made aware of the controversial nature of the Thompson and Schwer paper.

While the demographic data provided by the Thompson and Schwer survey are interesting, the cost estimates derived from them are problematic and unreliable. There is no doubt that pathological 
gambling behaviors cause social costs. We may all agree that we would like to minimize the social costs, along with the wealth transfers and internalized costs due to pathological gambling behavior. But social costs are decreases in societal wealth, while transfers merely redistribute existing wealth, and internalized costs do not affect third parties. These effects are fundamentally different. Lumping them together produces a deceptive measure of social costs.

As this literature develops, researchers will eventually hone the ability to measure social costs. In the meantime, policymakers should be aware that this is a new area of research, and the results are not always reliable, even with the best intentions and efforts of the authors of such studies.

\section{NOTES}

1. Also see Walker (2007) for a discussion of more general problems in the cost-benefit analysis of gambling.

2. This section is based on Walker and Barnett (1999) and Walker (2003).

3. For example, "social costs" were the focus of the Whistler Symposium (2000) sponsored by the Canadian Centre on Substance Abuse. The papers from the symposium were published in Journal of Gambling Studies 19(2), summer 2003. The Alberta Gaming Research Institute sponsored another conference on social costs in Banff in 2006.

4. "Wealth" refers generally to well-being. See Walker and Barnett (1999) and Walker (2003) for a detailed explanation. For readers who remember their freshmen economics class, a social cost can be represented by a movement from a point on the production possibilities frontier (PPF) to a point under the frontier. The use of community indifference curves can be used to illustrate the change in social welfare resulting from the social cost. For a complete discussion, see Walker (2007).

5. An increase in the interest rate due to loan defaults would be a pecuniary externality. This class of externality is not generally seen by economists as a justification for government intervention. 
For a detailed explanation of externalities related to pathological gambling, see Walker and Barnett (1999) and references therein.

6. This is not to say that the monetary estimates are unimportant. A detailed discussion of them is beyond the scope of this paper.

7. A similar argument applies to professional gamblers; that issue is addressed by Walker (2001).

8. Simply because involuntary unemployment is bad does not justify its being classified as a social cost.

9. In the context of the PPF model mentioned in note 4, but with two individuals' wealth on the axes, a transfer is illustrated by a movement along the frontier, not beneath it.

10. Thompson and Schwer (2005, p. 80) explain, "For purposes of clarity and comparisons, and in recognition of past efforts to calculate specific costs for matters such as arrests and [court] appearances, we will use the cost calculations identified in the 1996 Wisconsin study." Yet, for the costs of arrest they use a $\$ 2,900$ figure (p. 82) rather than the $\$ 500$ figure from the Wisconsin study (Thompson, Gazel \& Rickman, 1996, p. 19). The reason for doing this is not explained.

11. The revised social cost estimate of $\$ 1,579$ is $8 \%$ of the $\$ 19,711$ cost used by Thompson and Schwer. The $\$ 25$ and $\$ 44$ million figures represent $8 \%$ of the $\$ 314$ and $\$ 545$ million figures, respectively.

12. This is the published version of the paper cited by Thompson and Schwer.

13. The NRC (1999, p. 186) explains, "Most [gambling studies] have appeared as reports, chapters in books, or proceedings at conferences, and those few that have been subject to peer review have, for the most part, been descriptive pieces. As this research evolves, it should be subjected to peer review to help ensure that it indeed is advancing the body of knowledge."

14. For example, it is odd that Thompson and Schwer did not reference any of the "Whistler Symposium" papers (Journal of Gambling Studies, Vol. 19, No. 2 [2003]), considering that Thompson participated in the symposium. 


\section{REFERENCES}

"Milking the New Buffalo." (2003, March). Fedgazette. Federal Reserve Bank of Minneapolis. [Online]. Available at http://www.minneapolisfed.org/pubs/fedgaz/03-03/milking.cfm. [Retrieved December 11, 2007]

National Research Council. (1999). Pathological Gambling: A Critical Review. Washington, DC: National Academy Press. [Online]. Available at http://www.nap.edu. [Retrieved December 11, 2007]

Politzer, R., Morrow, J. \& Leavey, S. (1985). "Report on the CostBenefit/Effectiveness of Treatment at the Johns Hopkins Center for Pathological Gambling." Journal of Gambling Behavior, 1: 131142.

Thompson, W., Gazel, R. \& Rickman, D. (1996). The Social Costs of Gambling in Wisconsin (Report 9, No. 6). Thiensville, Wl: Policy Research Institute.

Thompson, W., Gazel, R. \& Rickman, D. (1999). "Social Costs of Gambling: A Comparison of Nutmeg and Cheese State Gamblers." Gaming Research \& Review Journal, 5 (1): 1-16.

Thompson, W., \& Quinn, F. (1999). An Economic Analysis of Machine Gambling in South Carolina (Report to the Educational Foundation). Columbia, SC: South Carolina Policy Council.

Thompson, W., \& Schwer, K. (2005). "Beyond the Limits of Recreation: Social Costs of Gambling in Southern Nevada." Journal of Public Budgeting, Accounting \& Financial Management, 17 (1): 62-93.

Walker, D. (2001). "Is Professional Gambling a Directly Unproductive Profit-Seeking (DUP) Activity?" International Gambling Studies, 1: 177-183.

Walker, D. (2003). "Methodological Issues in the Social Cost of Gambling Studies." Journal of Gambling Studies, 19 (2): 149184.

Walker, D. (2007). The Economics of Casino Gambling. New York: Springer. 
Walker, D., \& Barnett, A. (1999). "The Social Costs of Gambling: An Economic Perspective." Journal of Gambling Studies, 15 (3): 181212. 